\title{
BMJ Open Do failures in non-technical skills contribute to fatal medical accidents in Japan? A review of the 2010-2013 national accident reports
}

\author{
Masashi Uramatsu, ${ }^{1}$ Yoshikazu Fujisawa, ${ }^{1,2}$ Shinya Mizuno, ${ }^{3}$ Takahiro Souma, ${ }^{4}$ \\ Akinori Komatsubara, ${ }^{5}$ Tamotsu Miki $^{1}$
}

To cite: Uramatsu M,

Fujisawa Y, Mizuno S, et al. Do failures in non-technical skills contribute to fatal medical accidents in Japan? A review of the 2010-2013 national accident reports. BMJ Open 2017;7:e013678. doi:10.1136/bmjopen-2016013678

- Prepublication history for this paper is available online To view these files please visit the journal online (http://dx.doi.org/10.1136/ bmjopen-2016-013678).

Received 29 July 2016 Accepted 18 January 2017

CrossMark

For numbered affiliations see end of article.

Correspondence to Dr Masashi Uramatsu; masura@tokyo-med.ac.jp

\section{ABSTRACT}

Objectives: We sought to clarify how large a proportion of fatal medical accidents can be considered to be caused by poor non-technical skills, and to support development of a policy to reduce number of such accidents by making recommendations about possible training requirements.

Design: Summaries of reports of fatal medical accidents, published by the Japan Medical Safety Research Organization, were reviewed individually. Three experienced clinicians and one patient safety expert conducted the reviews to determine the cause of death. Views of the patient safety expert were given additional weight in the overall determination.

Setting: A total of 73 summary reports of fatal medical accidents were reviewed. These reports had been submitted by healthcare organisations across Japan to the Japan Medical Safety Research Organization between April 2010 and March 2013.

Primary and secondary outcome measures: The cause of death in fatal medical accidents, categorised into technical skills, non-technical skills and inevitable progress of disease were evaluated. Non-technical skills were further subdivided into situation awareness, decision making, communication, team working, leadership, managing stress and coping with fatigue.

Results: Overall, the cause of death was identified as non-technical skills in 34 cases (46.6\%), disease progression in 33 cases (45.2\%) and technical skills in two cases (5.5\%). In two cases, no consensual determination could be achieved. Further categorisation of cases of non-technical skills were identified as 14 cases $(41.2 \%)$ of problems with situation awareness, eight $(23.5 \%)$ with team working and three $(8.8 \%)$ with decision making. These three subcategories, or combinations of them, were identified as the cause of death in 33 cases $(97.1 \%)$.

Conclusions: Poor non-technical skills were considered to be a significant cause of adverse events in nearly half of the fatal medical accidents examined. Improving non-technical skills may be effective for reducing accidents, and training in particular subcategories of non-technical skills may be especially relevant.

\section{Strengths and limitations of this study}

- This study suggests that deficiency in nontechnical skills may have been significant in fata medical accidents in Japan.

- The cause of death was determined at the category level and by using subcategories set out in a well-established classification of non-technical skills.

- Training in particular subcategories of nontechnical skills may be especially relevant in increasing patient safety.

- Reviewing the full text of incident reports would provide a fuller picture of the cause of incidents and probably be less ambiguous.

- Further analysis with a bigger group of reviewers might be helpful.

\section{INTRODUCTION}

Since the Institute of Medicine (IOM) in the USA issued 'To Err is Human' in 1999, much effort has been made to improve patient safety. For all this, however, medical errors have not been eliminated. ${ }^{1}$ The importance of non-technical skills (NTS) in preventing medical errors has gradually become more obvious, and has been discussed since the beginning of the 2000s. ${ }^{2}{ }^{3}$ This insight emerged from fields such as aviation, with the realisation that it was not sufficient to focus only on technical skills (TS) arising from the Tenerife crash in 1977. ${ }^{4}$ Analysis of cockpit conversations identified critical failures caused by lack of NTS, such as leadership, communication and decision making. ${ }^{5}$ To reduce errors and improve performance of flight crews, NTS training was developed. ${ }^{6}$ Before people realised that NTS might be significant in medical accidents, the concepts and training systems used in pilot training had already been introduced to other highrisk settings such as nuclear power facilities, 
military bases and shipping. ${ }^{4}$ It has also been shown that highly dedicated and trained health professionals make errors because of organisational complexity. ${ }^{7}$ These errors cause incidents in medical settings, some of which could be attributed to lack of NTS rather than TS. ${ }^{8}$ For example, one study showed that non-technical skills for surgeons (NOTSS) had an effect on patient deaths following orthopaedic and trauma surgery in 112 cases of the 257 studied. $^{9}$

Several tools and programmes have been developed over the last 15 years to improve NTS in healthcare fields. ${ }^{10}$ A variety of practical training programmes have been developed in various subfields, including the scrub practitioners' list of intraoperative non-technical skills (SPLINTS), ${ }^{11}$ NOTSS ${ }^{12}$ and anaesthetists non-technical skills (ANTS). ${ }^{13}$ These programmes may have improved the NTS of surgeons and nurses, ${ }^{14}$ but most studies have been unable to report any direct improvement in outcomes for patients, ${ }^{15}$ except a reduction in time in the resuscitation room and before starting key investigations. ${ }^{16}$

Several reports have tried to introduce the basic concepts of NTS ${ }^{17} 18$ and simulation-based training programmes to support their development, ${ }^{19}$ including in Japan. There has, however, been no clear evidence of the impact and/or contribution of NTS to adverse events in Japan. The Division of Adverse Events Prevention in the Japan Council for Quality Health Care (JCQHC), established in 1995 by the Ministry of Health and Welfare, has conducted a project since 2004 to collect medical nearmiss/adverse-event information, with a view to prevent adverse medical events and promote patient safety. As a neutral third-party organisation, the JCQHC publishes periodic reports analysing aggregated results of medical near-miss/adverse-event information from 965 selected healthcare institutions in Japan. ${ }^{20}$ The 2013 JCQHC annual report included information about 3049 adverse medical events, ${ }^{20}$ with or without malpractice. The classification of the causes of these events seemed to suggest that technical and NTS might be relevant. For example, inadequate coordination, misjudgement and busy working conditions may be linked to inadequate NTS. ${ }^{21}$ It is, however, still unclear whether NTS cause medical accidents in Japanese healthcare settings, because the JCQHC report does not standardise parameters or make a scientific classification of category of cause. ${ }^{22}$

The purpose of this study is to clarify how large a proportion of fatal medical accidents can be considered to be caused by poor NTS, by reviewing published data about medical accidents in Japan. It also aims to support development of a policy to reduce fatal medical accidents by making recommendations about possible training requirements.

\section{MATERIALS AND METHODS}

Data sources

This study drew on 73 summary reports of medical accidents filed between April 2010 and March 2013 with the
Japan Medical Safety Research Organization (JMSRO). The JMSRO, which was established in 2010 with support from the Ministry of Health and Welfare (MHW), is a third-party organisation that investigates fatal medical adverse events. It organises committees to investigate the causes of care-related deaths of hospitalised patients following requests from hospitals, and with the consent of the bereaved families. The investigation committees each have around 10 members, who are specialists in the disease area, anatomists and lawyers. Each specialist is a member of one of the 40 medical societies in Japan. The JMSRO has disclosed summaries of the results of these investigations since 2010, via its website.

The reports were between two and 12 pages long, and all included key words, age and sex of the patients concerned, summary of clinical course, results of autopsy, result of analysis of cause of death, medical evaluation of the case, suggestions to prevent similar events in the future and a conclusion, plus the names of the members of investigation committee.

\section{Data review process}

We followed a review process previously used for analysis of surgical errors in closed claims, with an independent review by several primary clinicians and a secondary review by another expert. ${ }^{23}$ Our study used three medical doctors as primary reviewers, all of whom were experienced clinicians, and who read Safety At The Sharp End in Japanese ${ }^{24}$ before the review process. To standardise their judgments, they also discussed the causes of death in 10 of the 73 cases immediately before the individual reviews.

The primary reviewers independently reviewed all 73 cases, and determined the most probable cause of death in each case using the guidelines set for this study to determine the cause of death (see table 1). This had three categories: NTS, ${ }^{4}$ TS or death from disease progression (D).

Reviewers were asked to decide whether the cause of death was NTS, TS or D. If they decided on NTS, they were asked to choose a subarea from table 1 . They also highlighted sentences or words in the reports that supported their judgement.

In the second stage, an expert reviewed the cases and decided the cause of death based on the same categories and elements as the primary reviewers, also highlighting sentences or words to support his judgement. The expert reviewer was well versed in patient safety and NTS, having carried out research into patient safety in a governmental institution for 3 years, and worked as director of patient safety in three university hospitals for 11 years. He published a book about NTS in $2014 .{ }^{25}$ The judgement of this expert was weighted more heavily than the other clinicians.

Integrating decisions of primary reviewers and expert To integrate decisions about causes of death from all reviewers into a final judgement, we allocated one point 
Table 1 Guidelines to determine the cause of death

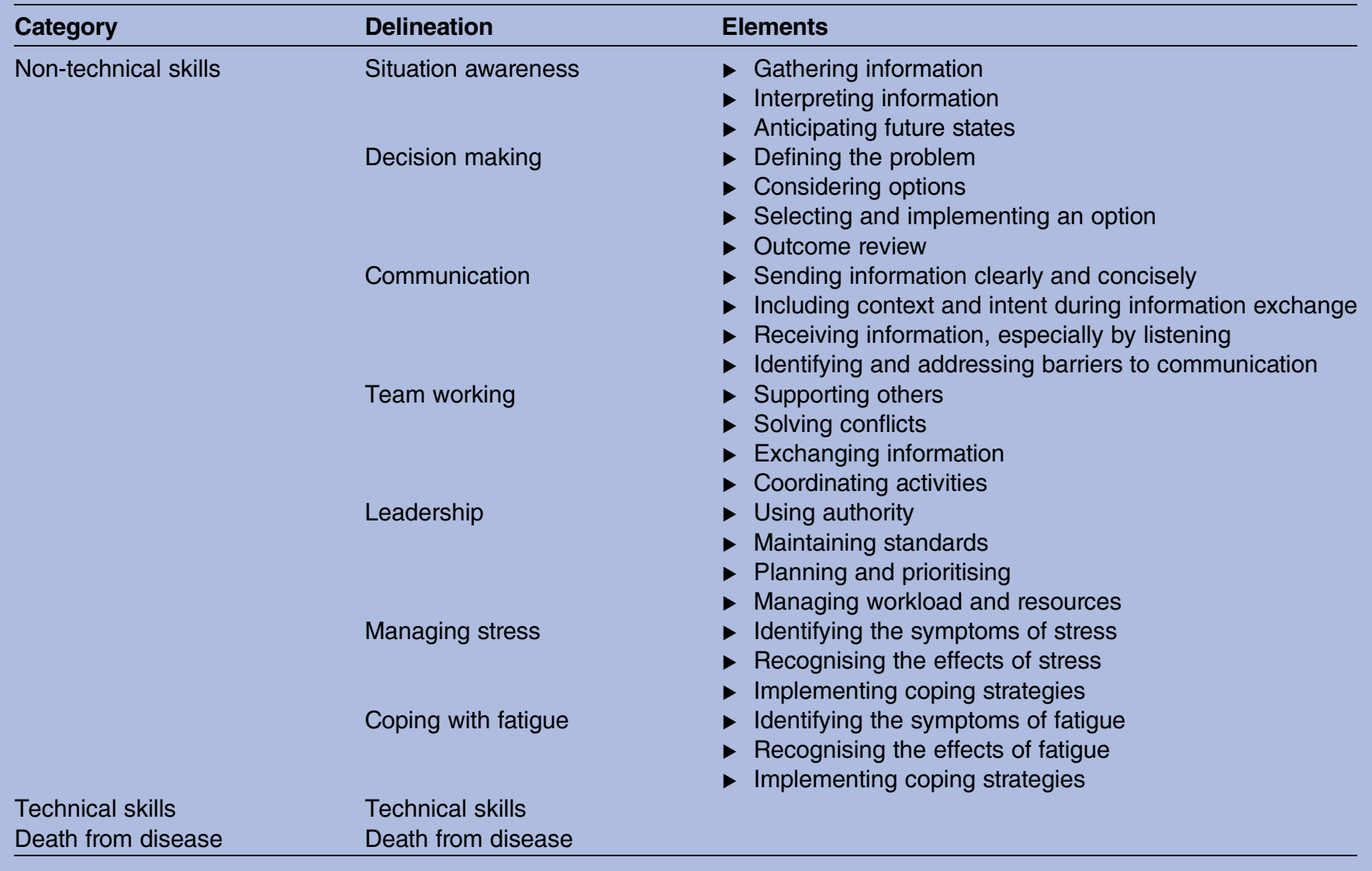

to the result of each primary reviewer, and two points to the expert. We added the total number of points in each category and any category with three points or more was considered to be the cause of death. If the scores for two categories were the same, the cause of death was considered to be indeterminable. We then examined the frequency with which various factors were identified as the cause of death.

\section{RESULTS}

\section{Characteristics of the 73 cases}

The largest age group was patients in their $70 \mathrm{~s}$, followed by those in their 60s. In total, 46 patients were man and 27 woman. The analysis of keywords, results of the autopsy and analysis of cause of death by the JMSRO investigation showed that the most frequent cause of death was haemorrhage ( 15 cases, $20.5 \%$ ) followed by heart and/or respiratory failure and pneumonia (5 cases each, 6.8\%) (table 2).

The types of medical intervention provided during the patient's period of hospitalisation were divided into noninterventional and interventional. The interventions were divided into surgery and others. No medical interventions were given in 18 cases. Interventions other than surgery included catheterisation for ischaemic heart disease or arrhythmia (7 cases), medication (6 cases) and others (13 cases) (table 3).
Table 2 Cause of death determined by the Japan Medical Safety Research Organization's (JMSRO) investigation of 73 cases

\begin{tabular}{|c|c|c|}
\hline \multicolumn{3}{|l|}{ Diagnosis } \\
\hline Haemorrhage & 15 & $\begin{array}{l}\text { Others } 22 \\
\text { Air embolism }\end{array}$ \\
\hline Heart and/or respiratory & 5 & Amyloidosis \\
\hline failure & 5 & Breast cancer \\
\hline Pneumonia & & $\begin{array}{l}\text { Cerebral ischemia } \\
\text { Coronary rupture }\end{array}$ \\
\hline AMI & 3 & Hyperkalaemia \\
\hline Cardiac tamponade & 3 & Hypoglycaemia \\
\hline Arrhythmia & 3 & Intracranial hypertension \\
\hline Intestinal perforation & 3 & $\begin{array}{l}\text { Liver abscess } \\
\text { Liver failure }\end{array}$ \\
\hline Peritonitis & 2 & Malignant lymphoma \\
\hline Sepsis & 2 & Old age \\
\hline Hypoxaemia & 2 & Pancreatic injury \\
\hline Anaphylaxis & 2 & Pancreatitis \\
\hline $\begin{array}{l}\text { Subarachnoid } \\
\text { haemorrhage }\end{array}$ & 2 & $\begin{array}{l}\text { Pulmonary embolism } \\
\text { Pulmonary haemorrhage } \\
\text { Renal abscess }\end{array}$ \\
\hline Infection & 1 & Renal failure \\
\hline Intestinal necrosis & 1 & Stent thrombosis \\
\hline $\begin{array}{l}\text { Cerebral infarction } \\
\text { Unknown }\end{array}$ & 1 & $\begin{array}{l}\text { Transplantation-related } \\
\text { death }\end{array}$ \\
\hline & 1 & $\begin{array}{l}\text { Trousseau syndrome } \\
\text { Tumour embolisms }\end{array}$ \\
\hline
\end{tabular}


Table 3 Cross tabulation between age groups and interventions performed during hospitalisation in 73 cases

\begin{tabular}{|c|c|c|c|}
\hline \multirow[b]{3}{*}{ Age } & \multicolumn{3}{|c|}{ Intervention } \\
\hline & \multirow[b]{2}{*}{-} & \multicolumn{2}{|l|}{+} \\
\hline & & Surgery & Others \\
\hline$<40$ & 0 & 1 & 4 \\
\hline $41-69$ & 8 & 12 & 11 \\
\hline$>70$ & 10 & 14 & 13 \\
\hline
\end{tabular}

\section{Primary and expert review}

NTS were considered the cause of death in nearly half of all cases (range 31.5-58.9\%), and progression of disease in around $40 \%$ of cases (range $31.5-53.4 \%$ ). TS were considered the cause in $10 \%$ of cases (range 4.1-13.7\%). Reviewer C was unable to select a cause in one case. The expert selected NTS), disease (D) and TS as the cause of death in $31(42.5 \%), 35(47.9 \%)$ and 7 cases $(9.6 \%)$.

\section{Integrating primary reviewer and expert views}

By combining opinions from all reviewers, NTS, disease progression and TS were selected as the definitive cause of death in $34(46.6 \%), 33(45.2 \%)$ and $2(5.5 \%)$ cases. In two cases, no consensual determination could be obtained, as the scores for TS and disease were equal (figure 1).

\section{Assessment of sub-category of NTS}

Overall, of the 34 cases with NTS identified as the cause of death, there were 14 cases $(41.2 \%)$ of problems with situation awareness, eight $(23.5 \%)$ with team working and three $(8.8 \%)$ with decision making. These three subcategories, or combinations of these, were determined as the cause of death in 33 cases $(97.1 \%)$. Out of 292 reviews (four reviewers each reviewing all 73 cases), NTS were given as a cause of death 140 times. Of these 140, 65 reviews identified problems with situation awareness, 41 with team working and 31 with decision making. Communication skills were identified as a problem twice and leadership once. Neither stress management nor fatigue management were selected at all (figure 2).

\section{DISCUSSION}

Our study had four major findings. First, a lack of NTS could be identified as a cause of death in almost half of cases studied in Japan. Second, a lack of situation awareness, team working and decision making were considered the most frequent causes of death in NTS cases. Third, inadequate TS were considered the cause of death in only four cases in this study. Finally, in $42.5 \%$ of cases, death was considered to have occurred because of progression of disease.

The strength of this study is that the cause of death was determined at the category level and by using subcategories set out in a well-established classification of NTS. This study is also the first of which we are aware to show the possibility of a relationship between deficiencies in NTS and fatal medical events in Japan. Although several authors have described a correlation between NTS and medical malpractice, they have not used wellestablished categories of NTS. For example, a review of malpractice claim cases and errors used some NTS, including cognitive factors, communication and patientrelated factors. $^{26}$

Other authors mention the link among breakdown of communication, an NTS and injury in surgical patients. $^{2728}$ In a study of the causes of near misses in a

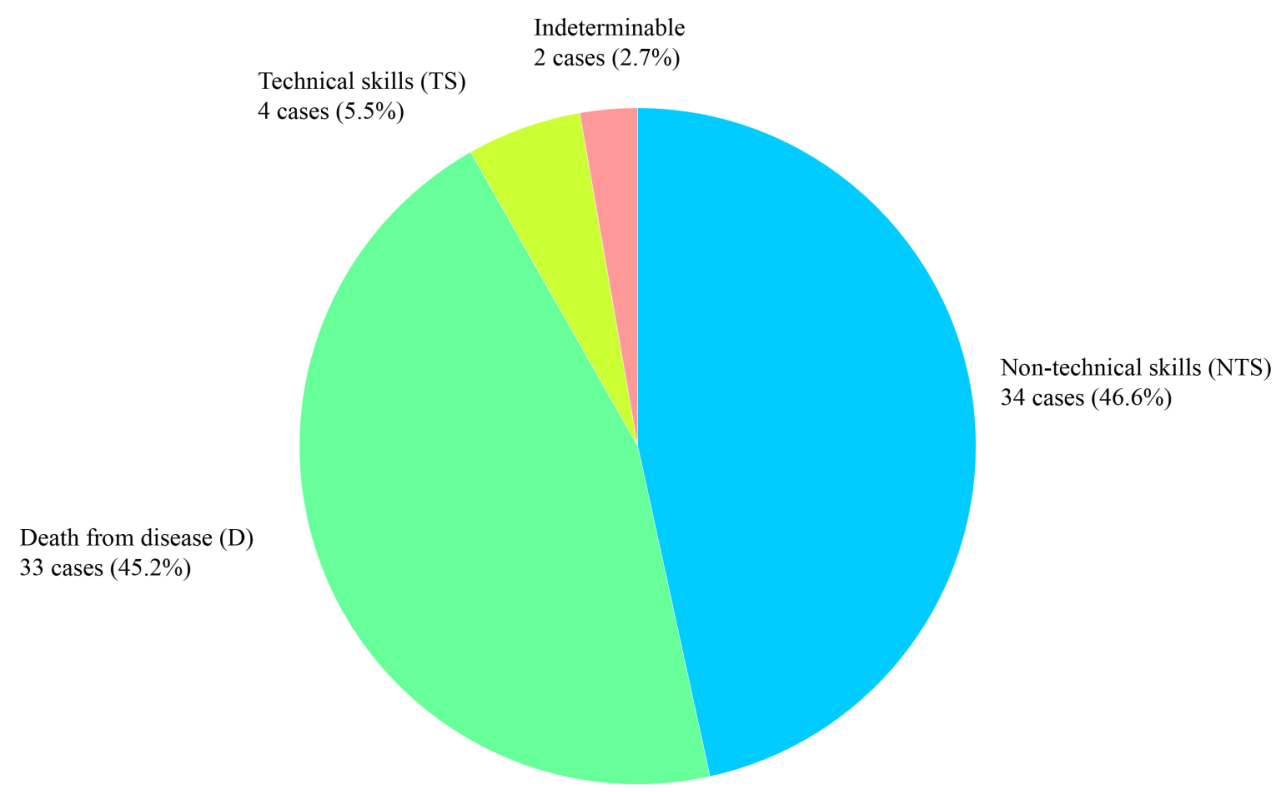

Figure 1 Definitive cause of death determined by the review of the 73 cases. 

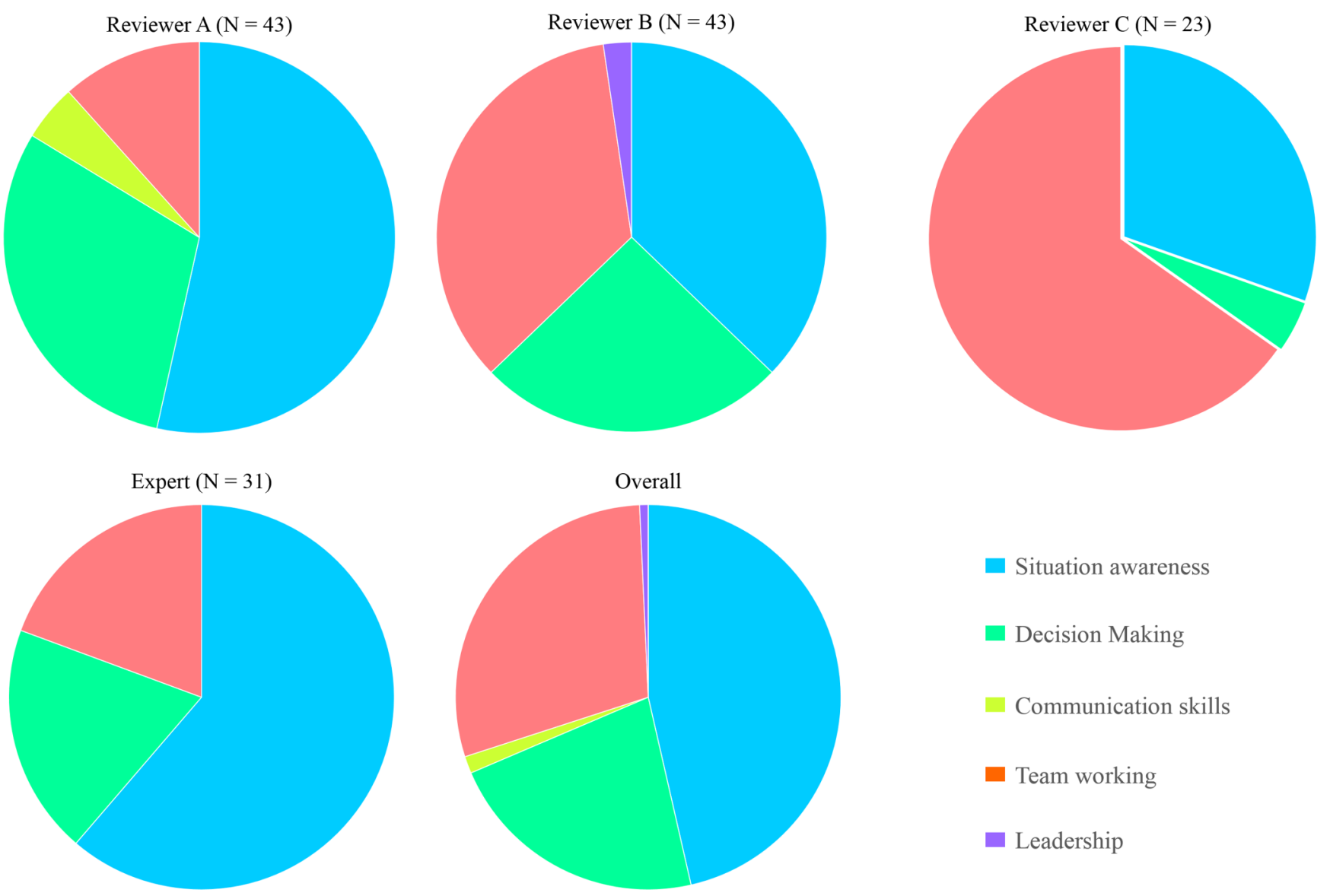

Figure 2 Determination of subcategories of non-technical skills. The pie charts show results for each reviewer and overall results (summed).

neonatal intensive care unit, mental/physical workload, communication failures and medical devices were suggested as possible causes of near misses. ${ }^{29}$ The categories of NTS in these studies were not classified taxonomically or theoretically, although several of the reports have included some concepts or elements related to NTS. In this study, we used a well-established classification of NTS to assess whether these could be considered a crucial cause of medical accidents.

This study, however, has three weaknesses. First, it relied on summary reports drawn up from full investigation reports. The full reports contain more information, such as conversations between medical staff and more detailed descriptions. Access to these full reports, however, is not permitted by law. Detailed JMSRO reviews are kept confidential, to enable free and deep discussion among committee members. Reviewing the full text of reports rather than summary reports might provide a fuller picture of the causes of incidents and probably be less ambiguous, but is not possible under normal circumstances. We do not know, on how many occasions the factors identified in the summary reports are actually present, but cause no problems. This limitation would also affect our results about the links between particular subcategories of NTS and adverse medical events. The second weakness is the organisation of the review. This study used three primary reviewers and one patient safety expert. The three primary reviewers were experienced clinicians (one in each of internal medicine, surgery and psychiatry) and had gained knowledge of the concept of NTS through reading the textbook. As they had different skill sets ${ }^{30}$ and experience, a postreview focus group discussion between the three primary reviewers might have been effective in improving the quality of the primary review, and particularly in increasing consistency between reviewers. Finally, the non-technical factors were 'unpacked' into various types of skills, whereas the technical and disease-related elements were left as a single category for the analysis. This would probably have increased the prominence of non-technical elements within the study.

The rate at which deficiencies in subcategories of NTS are considered to be causes of adverse medical events is almost same as the rate of NOTSS-related deaths in surgical patients in England and Wales. ${ }^{9}$ Our findings were also consistent with a previous report showing that most healthcare incidents can be attributed to failures in NTS rather than TS. ${ }^{8}$ Our study suggests that some categories of NTS are much more strongly associated with adverse medical accidents than others. Although, it is not possible to analyse statistically because of the small number 
of reviewers, there was wide variation between reviewers' determination of cause of death. For example, poor team working was considered to contribute in one-eighth of NTS cases by Reviewer A, but in two-thirds by Reviewer C. As the analysts are critical to the quality of the analysis, ${ }^{31}$ the variation among reviewers' determination may arise from the difference in focus of the reviewers: in other words, each paid attention to different facts in the reports.

There are many theories suggesting that the causes of accidents are multifactorial; for example, that they do not usually arise from a single cause but from a chain of failures, described as being like getting through layers of Swiss cheese, or the interaction of a number of factors, ${ }^{32}$ and the relationship between clinicians and managers. ${ }^{33}$ The differences may therefore arise from the reviewers' different focus in reading the description of the event. Another possible factor is ambiguity of subcategories. Even if the reviewers focused on the same event as the cause of death, it may be difficult to distinguish between related subcategories. ${ }^{34}$

Leadership, managing stress and coping with fatigue were not identified at all in this study. Although situation awareness, teamwork and task management were well described in incident reports, ${ }^{35}$ leadership, managing stress and coping with fatigue may not be described in summary reports of adverse medical events. Inadequate TS were considered the cause of death in only four cases in this study. This is much lower than another study, ${ }^{9}$ in which failures of TS were identified as an issue in $25.4 \%$ of surgical deaths. The summary reports analysed in our study seldom mentioned deficiency of TS. We were unable to access more detailed information, such as videos recorded during operations, or to assess the quality of TS through the review process. In almost half of cases, death was considered to have occurred because of progression of disease, rather than a lack of skills, whether technical or non-technical. In these cases, bereaved family members might have demanded a third-party investigation because of problems in the doctor-patient relationship or lack of medical accountability. ${ }^{36} 37$

Future studies should consider the appropriate number of reviewers, their specialties and experience and their familiarity with the analysis of accidents. Further analysis with a bigger group of reviewers might be helpful. Further research about links between subcategories of NTS and adverse medical events, or correlations between types of NTS would also be useful. Despite these limitations, however; and the need for further studies with other data to clarify whether NTS are a cause of medical accidents, this study suggests that a shortage of NTS is one of the possible causes of medical errors. Our results suggest that improving NTS may be effective in reducing accidents. Training in particular subcategories of NTS may be especially relevant in increasing patient safety.

\section{CONCLUSION}

This study suggests that poor NTS may be a significant cause of adverse events in quite a large proportion of fatal medical accidents in Japan. The novelty of this study is that the cause of death was determined at the category level and by using subcategories set out in a well-established classification of NTS. Our results suggest that improving NTS may be effective in reducing accidents. Training in particular subcategories of NTS may be especially relevant in increasing patient safety.

\section{Author affiliations}

${ }^{1}$ Department of Quality and Patient Safety, Tokyo Medical University, Tokyo, Japan

${ }^{2}$ Department of Social Engineering and Community Science, Miyagi University, Miyagi, Japan

${ }^{3}$ Faculty of Comprehensive Informatics, Department of Computer Science, Shizuoka Institute of Science and Technology, Shizuoka, Japan

${ }^{4}$ Division of Medical Safety Management, Chiba University Hospital, Chiba, Japan

${ }^{5}$ Department of Industrial and Management Systems Engineering, School of Creative Science and Engineering, Waseda University, Tokyo, Japan

Contributors MU participated in the design of the study and was one of the primary reviewers of the JMSRO data. YF participated in the design of the study and preparation of the review. SM contributed to the data analysis. AK provided the classification of non-technical skills. MT provided advice on interpretation of results as an experienced clinician. All authors contributed to development and writing of the manuscript and agreed the final version for submission.

Funding This work was supported by JSPS KAKENHI grant number 26293114.

Competing interests None declared.

Provenance and peer review Not commissioned; externally peer reviewed.

Data sharing statement Extra data can be accessed via the Dryad data repository at http://datadryad.org/ with the doi:10.5061/dryad.kq307

Open Access This is an Open Access article distributed in accordance with the Creative Commons Attribution Non Commercial (CC BY-NC 4.0) license, which permits others to distribute, remix, adapt, build upon this work noncommercially, and license their derivative works on different terms, provided the original work is properly cited and the use is non-commercial. See: http:// creativecommons.org/licenses/by-nc/4.0/

\section{REFERENCES}

1. Landrigan $\mathrm{CP}$, Parry GJ, Bones $\mathrm{CB}$, et al. Temporal trends in rates of patient harm resulting from medical care. $N$ Engl J Med 2010;363:2124-34.

2. Anderson ES, Lennox AI, Petersen SA. Learning from lives: a mode for health and social care education in the wider community context. Med Educ 2003;37:59-64.

3. Blum RH, Raemer DB, Carroll JS, et al. Crisis resource management training for anaesthesia faculty: a new approach to continuing education. Med Educ 2004;38:45-55.

4. Flin R, O'Connor P, Crichton M. Safety at the sharp end: a guide to non-technical skills. Surrey. England: Ashgate, 2008.

5. Beaty D. The naked pilot: the human factor in aircraft accidents. Shrewsbury, England: Airlift Publishing, 1995.

6. Wiener E, Kanki B, Helmreich R, eds. Cockpit resource management. San Diego: Academic Press, 1993.

7. Vincent C. Patient safety. 2nd edn. Oxford, UK: Wiley-Blackwell, 2010:123-4.

8. Bogner M, ed. Misadventures in health care. NJ: LEA, 2004

9. Panesar SS, Carson-Stevens A, Mann BS, et al. Mortality as an indicator of patient safety in orthopaedics: lessons from qualitative analysis of a database of medical errors. BMC Musculoskelet Disord 2012;13:93. 
10. Fletcher GCL, McGeorge $\mathrm{P}$, Flin $\mathrm{RH}$, et al. The role of non-technical skills in anaesthesia: a review of current literature. $\mathrm{Br} J$ Anaesth 2002;88:418-29.

11. Flin R, Mitchell L, McLeod B. Non-technical skills of the scrub practitioner: the SPLINTS system. ORNAC J 2014;32:33-8.

12. Yule S, Rowley D, Flin R, et al. Experience matters: comparing novice and expert ratings of non-technical skills using the NOTSS system. ANZ J Surg 2009;79:154-60.

13. Patey R, Flin R, Fletcher G, et al. Developing a taxonomy of anesthetists' nontechnical skills (ANTS). In: Henriksen K, Battles JB Marks ES, et al. eds. Advances in patient safety: from research to implementation (volume 4: programs, tools, and products). MD: Agency for Healthcare Research and Quality, 2005.

14. Mishra A, Catchpole K, Dale T, et al. The influence of non-technical performance on technical outcome in laparoscopic cholecystectomy. Surg Endosc 2008;22:68-73.

15. Piromchai $\mathrm{P}$, Avery $\mathrm{A}$, Laopaiboon $\mathrm{M}$, et al. Virtual reality training for improving the skills needed for performing surgery of the ear. nose or throat. Cochrane Database Syst Rev 2015;(9): CD010198.

16. Georgiou A, Lockey DJ. The performance and assessment of hospital trauma teams. Scand J Trauma Resusc Emerg Med 2010;18:66.

17. Takahiro S. Patient safety in OR (in Japanese). Masui 2012;61 (Suppl):183-8.

18. Nakajima K. Non-technical skills for medical specialists to improve team performance and patient safety (in Japanese). Shinkeichiryo 2012;29:295-8.

19. Akaike M, Fukutomi M, Nagamune M, et al. Simulation-based medical education in clinical skills laboratory. J Med Invest 2012;59:28-35.

20. Japan Council for Quality Health Care. Project to collect medical near-miss/adverse event information 2013 annual report. Division of Adverse Event Prevention 2014:6-8.

21. Japan Council for Quality Health Care. Project to collect medical near-miss/adverse event information 2013 annual report. Division of Adverse Event Prevention, 2014:84.

22. Hirose M, Imanaka Y, Ishizaki T, et al. How can we improve the quality of health care in Japan? Learning from JCQHC Hospital accreditation. Health Policy 2003;66:29-49.

23. Agha RA, Fowler AJ, Sevdalis N. The role of non-technical skills in surgery. Ann Med Surg 2015;4:422-7.
24. Komatsubara A, Sogame H, Nakanishi M. Safety at the sharp end: a guide to non-technical skills (in Japanese). Tokyo, Japan: Kaibundo Publishing, 2012.

25. Souma T. Kanja anzen no tameno non-technical skills cho-nyuumon [Non-technical skills are fundamental for patient safety]. Osaka, Japan: MMEDICUS SHUPPAN, Publishers Co., Ltd, 2014.

26. Rogers OS, Gawande AA, Kwaan M, et al. Analysis of surgical errors in closed malpractice claims at four liability insurers. Surgery 2006;140:25-33.

27. Greenberg CC, Regenbogen SE, Studdert MD, et al. Communication breakdown and patient safety. J Am Coll Surg 2007;204:533-40.

28. Lingard L, Espin S, Whyte S, et al. Communication failures in the operating room: an observational classification of recurrent types and effects. Qual Saf Health Care 2004;13:330-4.

29. Tourgeman-Bashkin O, Shinar D, Zmora E. Causes of near misses in critical care of neonates and children. Acta Paediatr 2008;97:299-303.

30. Salmon PM, Stanton NA, Lenné M, et al. Human factors methods and accident analysis: practical guidance and case study applications. Surrey, England: Ashgate Publishing, 2011.

31. Grabowski M, You Z, Zhou Z, et al. Human and organizational error data challenges in complex, large-scale systems. Safety Science 2009;47:1185-94.

32. Reason J. Managing the risks of organizational accidents. Farnham, UK: Ashgate, 1997.

33. Reason J. Understanding adverse events: the human factor. In: Vincent C, ed. Clinical risk management: enhancing patient safety. 2nd edn. London, UK: BMJ Books, 2001.

34. Pezzolesi C, Manser T, Schifano F, et al. Human factors in clinical handover: development and testing of a 'handover performance tool' for doctors' shift handovers. Int J Qual Health Care 2013;25:58-65.

35. Rutherford JS, Flin R, Irwin A. The non-technical skills used by anaesthetic technicians in critical incidents reported to the Australian incident monitoring system between 2002 and 2008. Anaesth Intensive Care 2015;43:512-17.

36. Vincent C, Young M, Phillips A. Why do people sue doctors? A study of patients and relatives taking legal action. Lancet 1994;343:1609-13.

37. Bismark M, Dauer E, Paterson R, et al. Accountability sought by patients following adverse events from medical care: the New Zealand experience. CMAJ 2006;175:889-94. 